\title{
OPEN Children's role in the COVID-19 pandemic: a systematic review of early surveillance data on susceptibility, severity, and transmissibility
}

Katy A. M. Gaythorpe $\mathbb{1}^{1,3 凶}$, Sangeeta Bhatia $\mathbb{1}^{1,3}$, Tara Mangal ${ }^{1,3}$, H. Juliette T. Unwin $\mathbb{1}^{1,3}$, Natsuko Imai ${ }^{1,3}{ }^{1,}$, Gina Cuomo-Dannenburg ${ }^{1,3}$, Caroline E. Walters ${ }^{1,3}$, Elita Jauneikaite $1,{ }^{3}$, Helena Bayley $\mathbb{1}^{2}$, Mara D. Kont ${ }^{1}$, Andria Mousa ${ }^{1}$, Lilith K. Whittles ${ }^{1}{ }^{1}$, Steven Riley ${ }^{1}$ \& Neil M. Ferguson $\mathbb{1}^{1}$

SARS-CoV-2 infections have been reported in all age groups including infants, children, and adolescents. However, the role of children in the COVID-19 pandemic is still uncertain. This systematic review of early studies synthesises evidence on the susceptibility of children to SARS-CoV- 2 infection, the severity and clinical outcomes in children with SARS-CoV-2 infection, and the transmissibility of SARS-CoV-2 by children in the initial phases of the COVID-19 pandemic. A systematic literature review was conducted in PubMed. Reviewers extracted data from relevant, peer-reviewed studies published up to July 4th 2020 during the first wave of the SARS-CoV-2 outbreak using a standardised form and assessed quality using the NIH Quality Assessment Tool for Observational Cohort and Cross-Sectional Studies. For studies included in the meta-analysis, we used a random effects model to calculate pooled estimates of the proportion of children considered asymptomatic or in a severe or critical state. We identified 2775 potential studies of which 128 studies met our inclusion criteria; data were extracted from 99, which were then quality assessed. Finally, 29 studies were considered for the meta-analysis that included information of symptoms and/or severity, these were further assessed based on patient recruitment. Our pooled estimate of the proportion of test positive children who were asymptomatic

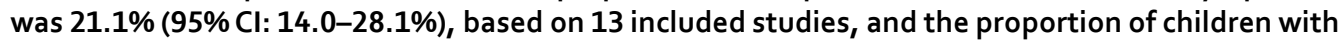
severe or critical symptoms was $3.8 \%(95 \% \mathrm{Cl}: 1.5-6.0 \%)$, based on 14 included studies. We did not identify any studies designed to assess transmissibility in children and found that susceptibility to infection in children was highly variable across studies. Children's susceptibility to infection and onward transmissibility relative to adults is still unclear and varied widely between studies. However, it is evident that most children experience clinically mild disease or remain asymptomatically infected. More comprehensive contact-tracing studies combined with serosurveys are needed to quantify children's transmissibility relative to adults. With children back in schools, testing regimes and study protocols that will allow us to better understand the role of children in this pandemic are critical.

Cases of atypical pneumonia were first reported in Wuhan City, China in late 2019. Since then, SARS-CoV-2 has spread rapidly across the globe and the World Health Organization declared COVID-19 a pandemic on March 11, 20201. As of May 12, 2021 there have been a total 158,685,909 reported cases and 3,299,666 deaths ${ }^{2}$. In the absence of effective therapeutics or vaccines early in the pandemic, countries implemented a range of non-pharmaceutical interventions (NPIs) to limit the spread of the virus.

${ }^{1}$ MRC Centre for Global Infectious Disease Analysis and WHO Collaborating Centre for Infectious Disease Modelling, Abdul Latif Jameel Institute for Disease and Emergency Analytics, Imperial College London, London, UK. ${ }^{2}$ Department of Physics, University of Oxford, Oxford, UK. ${ }^{3}$ These authors contributed equally: Katy A. M. Gaythorpe, Sangeeta Bhatia, Tara Mangal, H. Juliette T. Unwin and Natsuko Imai. These authors contributed equally: Gina Cuomo-Dannenburg, Caroline E. Walters and Elita Jauneikaite. ${ }^{\bowtie}$ email: k.gaythorpe@imperial.ac.uk 
Based on what was known about the role of children in the spread of influenza during previous pandemics, school closures were widely implemented with an estimated $80-100 \%$ of EU/EEA countries closing pre-schools, primary and secondary schools, and higher education institutions as the pandemic progressed from February 2020 in East Asia to late April across Europe and the Americas ${ }^{3-5}$. Widespread NPIs and effective "lockdowns", many including school-closures, have had a substantial role in suppressing transmission ${ }^{6}$. However, changes in contact patterns due to these measures have made it difficult to understand the extent to which children were infected by SARS-CoV-2 or were able to transmit SARS-CoV-2 onto others. Children and young adults represent a small proportion of the total reported cases of COVID-19 globally thus far, but the fraction of severe cases and deaths amongst this age group was small ${ }^{7}$. There was evidence $e^{7-12}$ for the age-dependency in clinical cases with severe cases and deaths concentrated in the elderly and amongst those with comorbidities in the early phase of COVID-19 pandemic. However, while there is consensus that children generally have milder clinical symptoms $\mathrm{s}^{7,13,14}$, it is important to note that early routine testing and diagnosis were restricted mainly to symptomatic cases requiring health care in most countries. Therefore, data reported by countries through routine surveillance systems early in the pandemic were likely to significantly under-estimate cases amongst those with mild or no symptoms.

In addition, the widespread social distancing (SD) measures, such as restrictions on gatherings, encouragement to work from home, and closures of bars and restaurants, have substantially impacted contact patterns between individuals ${ }^{15}$ and universal school-closures would have had significantly affected how much children interact with others. At the beginning of the pandemic, outbreaks of COVID-19 in schools had not been widely reported. However, national holidays and school closures in response to the pandemic would have changed the risk of exposure to SARS-CoV-2 infection by reducing the number of non-household contacts that children have. It has been suggested that children are less susceptible to SARS-CoV-2 infection due to differences in their innate immune system, which means a faster and broader immune response can be mounted ${ }^{16}$. However, a flat attack rate has been observed across different age groups in contact-tracing studies ${ }^{17}$, population-based infection surveys ${ }^{18}$ and retrospective seroprevalence surveys ${ }^{19,20}$. This is typical of a novel pathogen in a population with no prior immunity. There is also increasing evidence that the age-distribution of newly detected cases is shifting towards younger age groups which may been captured as a result of the expanded test capacity in many countries including the UK and USA compared to April $2020^{21}$. This shift has now starting to be reflected in increased hospitalisations amongst young adults (20-35 years old), but whether children will also be affected at the same rate is yet to be seen ${ }^{22}$.

The biggest uncertainty is whether children are intrinsically less infectious than adults and how much they contribute to onward transmission. Within household clusters, children are not often identified as the index case, but this is difficult to determine due to the age-dependent clinical symptoms and a larger proportion of infections in children appearing to be asymptomatic ${ }^{23}$. The correlation between clinical severity and transmissibility is also difficult to disentangle, since pre-symptomatic transmission has been shown to be an important driver of transmission within the population ${ }^{24-26}$. It is unclear to what extent mild and asymptomatic cases also contribute to onward transmission at any age ${ }^{27}$.

Policies around schools are being adjusted based on new evidence and the level of transmission in each country. With growing concern about the long-term developmental and mental health impacts of school closures on children, the safe re-opening of schools has become a priority across different governments. Understanding the role of children in SARS-CoV-2 transmission is therefore critical in guiding ongoing policy for schools conducting face-to-face education.

In this study we undertook a systematic review of the peer-reviewed literature, excluding pre-prints, to synthesize available data on three specific topics: (i) the susceptibility of children to SARS-CoV-2 infection; (ii) the severity and clinical outcomes in children with SARS-CoV-2 infection; and (iii) the transmissibility of SARS-CoV-2 by children. We conducted a meta-analysis of data collected to address these topics and discuss their implications for future public health policies. We limited this review to the early stages of the epidemic, reflecting the first pieces of evidence generated during an emerging outbreak, where large population serosurveys and extensive contact tracing were uncommon.

\section{Methods}

Literature search. Our methods adhere to the guidelines established by Preferred Reporting Items for Systematic Reviews and Meta-Analyses (PRISMA). Our study protocol was registered with PROSPERO (International Prospective Register of Systematic Reviews) under the identifier \#CRD42020184605.

We searched PubMed for "(sars-cov-2 OR $n$ Cov OR covid-19) AND children AND (infection or susceptibility or transmission or shedding or symptomatic)". As SARS-CoV-2 is a new human pathogen, we restricted our searches to records from 2019 and 2020. The initial search was conducted on May 6, 2020 and repeated on July 4, 2020. All records were imported into Covidence (v2014, accessed 2020), where duplicates were removed. Both the titles/ abstract and full-text screening were conducted by at least two independent reviewers and any conflicts resolved by consensus. Cohort studies, contact-tracing studies and population surveys were included. We excluded: (i) non-peer reviewed studies; (ii) case reports reporting fewer than 10 cases due to the high potential for bias and limited amount of information; (iii) papers focusing on vertical transmission; and (iv) non-English language papers. Full inclusion and exclusion criteria can be found in the Supplementary Information ("Inclusion and exclusion criteria" section).

Outcomes of interest were the risk in children of infection with COVID-19 following exposure i.e. aged distributed attack rate (up to 18 years of age); the risk of onward transmission of COVID-19 to contacts of an infected child i.e. secondary attack rates from a paediatric index case; and the proportion of symptomatic children 
and their disease severity (defined as mild disease/asymptomatic or severe disease requiring hospital care) of all children with confirmed COVID-19 infection.

Data extraction and quality assessment. Data extraction was performed by all investigators using an Excel spreadsheet. Data collected included the type of study (e.g. cohort), country of origin, number of patients or size of cohort considered, demographic information (including age and sex where available), clinical symptoms and severity, and seroprevalence or attack rates where available (Supplementary Information Table S1).

The methodological quality of included studies was assessed by two reviewers using 10-item questions, which we adapted from the NIH Quality Assessment Tool for Observational Cohort and Cross-Sectional Studies ${ }^{28}$ to assess the strength of evidence relating to our research questions specifically e.g. assessing if the case definitions were clearly specified in the study (Supplementary Information Tables S2 and S3). Studies that scored 7 or more points were classified as good, those that scored 5 or 6 points were rated as fair, and any study that scored fewer than 5 points was rated as poor at informing our research questions. Only studies rated fair or good were included in the meta-analysis, these were also further assessed using the criterion detailed in the supplementary material.

Data analysis. All extracted studies were filtered by topic, so data analysis was conducted only on studies including details on the quantity of interest, for example the number of individuals classed as asymptomatic. For the purposes of our analysis, we defined children as individuals aged 18 years or younger. The filtered studies were then checked for comparability, based on study type. Random effects modelling was performed using $\mathrm{R}$ package metaphor ${ }^{29}$ to produce estimates of the proportion of children considered asymptomatic or in a severe/ critical state. We used an empirical Bayes estimator for the level of heterogeneity and weighted by the size of the study population. Analyses were conducted using R package orderly version 1.1.29 $9^{30}$ in R version 3.6.3. Data and code are available from https://github.com/mrc-ide/child_covid19_lit_review.

\section{Results}

Literature search. A total of 2775 potential studies were identified through literature search , and 148 duplicates removed. Titles and abstracts for 2627 studies were screened. 633 studies fulfilled the inclusion criteria and were assessed for full-text evaluation. 505 full texts that did not meet the final inclusion criteria were excluded generating a final list of 128 studies included for systematic review analysis. The final number of studies included in the meta-analysis was 29 (Figure 1).

The study locations and study dates followed the pandemic trajectory with the majority of early studies conducted in China (45 studies $\left.{ }^{11,17,25,26,31-69}\right)$ and later studies conducted in Europe $\left(26\right.$ studies $\left.^{10,72-94}\right)$ and North America (12 studies ${ }^{97-106}$ ) (Fig. 2). There were no studies that matched the inclusion criteria from South America or Africa. We include the study timings to show potential spatial and temporal bias in our data. Supplementary Table S1 details the studies included with indicators for the information extracted from each; the quality assessment scores for each study are presented in Supplementary Table S3.

Susceptibility to infection. We identified only five studies ${ }^{17,18,61,75,107}$ that reported age-specific attack rates (AR) from contact tracing studies based on symptomatic surveillance for the index case and retrospective or prospective cohort studies, and these varied substantially between studies.

Based on contact-tracing studies in China, Bi et al. ${ }^{17}$, reported similar attack rates across all age groups in Shenzhen with a $7.4 \%$ attack rate in young children ( $<10$ years) compared to the population average of $6.6 \%$. Liu et al. ${ }^{61}$ estimated a higher attack rate in Guangdong Province amongst children aged $<10$ years and $10-19$ years (5.7\% and $4.0 \%$ respectively) compared to $20-29$ year olds with the lowest AR of $2.3 \%$. Conversely, PCR screening of 745 "highly suspected" children and 3174 adults found that adults were significantly more likely to test positive $(1.3 \% \text { in children vs } 3.5 \% \text { in adults })^{107}$. Those screened were individuals who had contact with a confirmed SARS-CoV-2 patient in the past 14 days or were identified as part of a familial outbreak in Guangzhou between 22 January and 20 February 2020.

From studies in Europe, Lavezzo et al. ${ }^{75}$, did not detect a single SARS-CoV-2 positive amongst children aged $<10$ years across two population wide surveys in Vo, Italy. They also found attack rates amongst older children aged 11-20 years were comparable to those observed in adult age groups. Similarly, population-based screening for SARS-CoV-2 in Iceland did not identify any SARS-CoV-2 positive children aged $<10$ years. In individuals deemed at high risk due to recent overseas travel or COVID-like symptoms and targeted for testing, $6.7 \%$ of children aged $<10$ years tested positive compared to $13.7 \%$ of those aged 10 years and above ${ }^{18}$. Prevalence by age group for relevant included studies is shown in Fig. 3.

We identified one study reporting age-specific seroprevalence from Geneva, Switzerland. Stringhini et al. found that young children aged 5-9 years had a significantly lower risk of being seropositive (RR 0.32, 95\% CI 0.11-0.63) compared to adults 20-49 years ${ }^{70}$. This variability in age-specific infection rates between studies was also reflected amongst the studies that reported SARS-CoV-2 infection prevalence in children and adults (Fig. $5)^{17,31,39,44,59,61,71,73,75,77,94,98,101,110-110}$.

Although the source of infection amongst children could not be assessed systematically, studies identified through the review suggest that transmission to children tended to occur within household settings from other family members in family clusters, although for the majority schools were closed during the first wave ${ }^{10,45}$. Many children had a history of close contact with at least one parent who was SARS-CoV-2 positive ${ }^{35,48,78}$. Chen et al. ${ }^{48}$ observed, based on small numbers, that this family aggregation was consistent amongst infants and pre-school children (7 of 8), and school-aged children (14 of 16) but not in adolescents (1 of 8). 


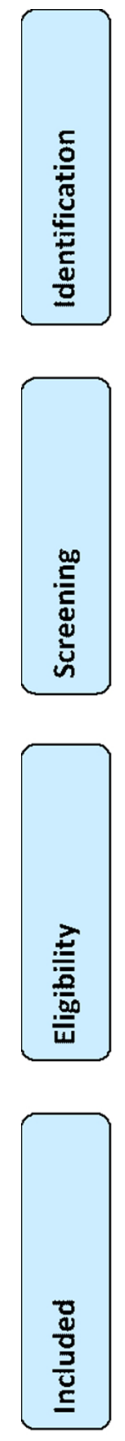

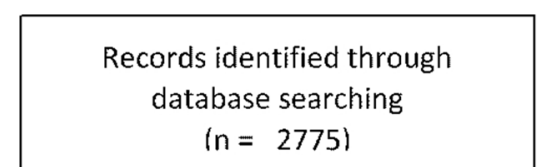

$(n=2775)$
Additional records identified through other sources

( $n=0$ )

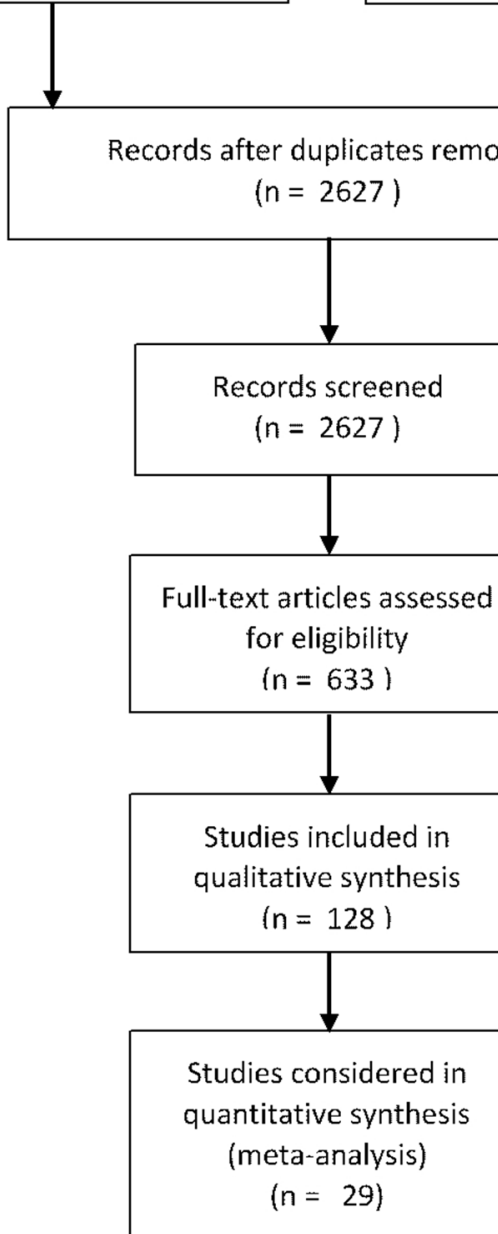

Figure 1. PRISMA flow chart detailing the literature search process.

Severity. Proportion asymptomatic. 29 studies with information on the size of the population considered COVID-19 positive by PCR and the number of individuals considered asymptomatic in those aged 18 or less were included $^{10,33,41,42,45-47,49,50,54,55,58,62,64,65,114,67,76,77,79,83,84,87,90,100,107,108,111,112}$. Most studies were cohort studies or case series; follow-up was sometimes not detailed. One study (Hu et al. ${ }^{113}$ ) was omitted during data extraction because the study population only selected asymptomatic children. The other studies were assessed for inclusion in the meta-analysis based on their recruitment of study participants and whether this was clear and unbiased. All studies are detailed in Table S4 in the supplementary material as well as a meta-analysis containing all studies. Fourteen studies fulfilled this additional criterion and the proportion of individuals considered asymptomatic in each included study is shown in Fig. 4. Our pooled estimate of asymptomatic children was $21.1 \%$ (95\% CI: $14.0-28.1 \%)$ with a $\tau^{2}$ (between-trial-variance) of 0.014 (95\% CI: $\left.0.004-0.057\right)$ and $\mathrm{I}^{2}$ statistic (percentage of variation due to heterogeneity, rather than chance) of $90.94 \%$ (95\% CI: 77.44-97.70). This indicates low variance between studies, but that the variance is mostly due to heterogeneity rather than chance. Information on the size of the population considered COVID-19 positive by RT-PCR and the number of individuals considered asymptomatic in those aged 18 or less were included in our analysis. A funnel plot of these studies is given in Figure S2 in the Supplementary Material and shows reasonable symmetry, suggesting low publication bias; however, as mentioned previously, there is geographic and temporal bias in the studies included. It is also noted that there have been issues in assessing symmetry of funnel plots for other works ${ }^{114,115}$. These estimates are consistent with estimates of asymptomatic infections in the wider population (20\%, 95\% CI: $17-25 \%)$ although this was found to vary between settings ${ }^{24}$.

Proportion severe or critical. Thirteen studies with information on the size of the population considered COVID-19 positive by PCR and the number of individuals considered severe or critical in those aged 18 or 
A

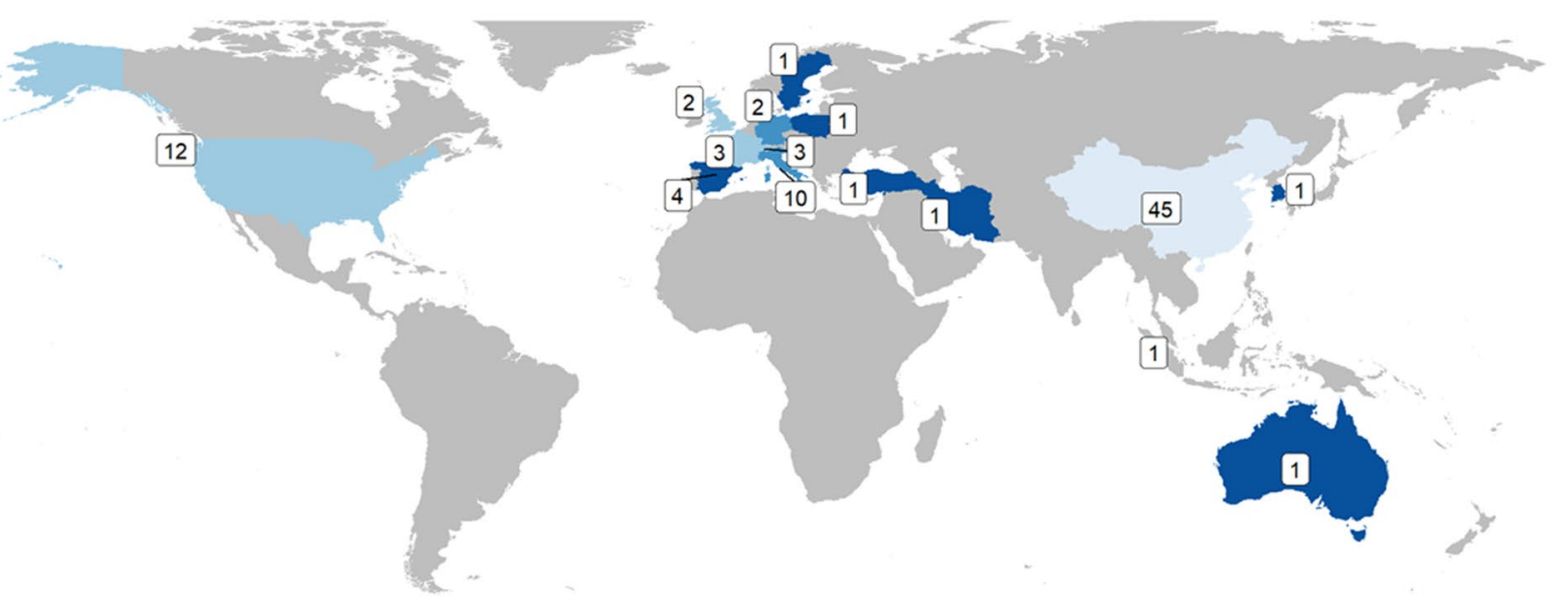

C

B

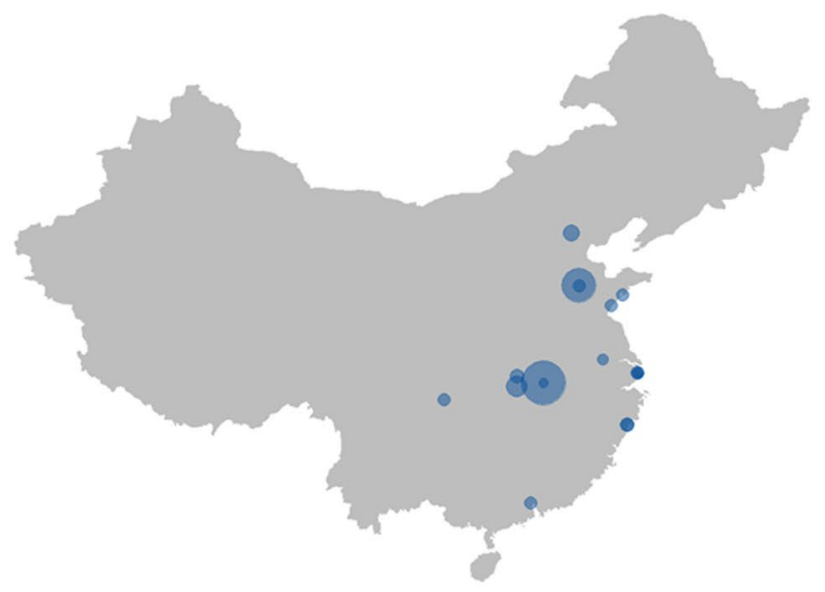

\author{
Earliest study start date $\square$ Dec $2019 \square$ Jan $2020 \square$ Feb $2020 \square$ Mar 2020
}

Figure 2. Distribution of studies over geography and time. (A) The distribution of studies globally where the label denotes number of studies in a country and colour denotes earliest recorded study start date. (B) Study locations in China where dot size corresponds to number of participants in entire study. (C) The distribution of studies in a subset of European countries where the label denotes number of studies in a country and colour denotes earliest recorded study start date. Studies including individuals from multiple countries, or without a city in China, were omitted from the map, $\mathrm{n}=10$.

younger were included ${ }^{10,41,46,49,50,54,64,65,76,84,100,116,117}$. Most studies were hospital-based and were based on PCRconfirmed cases only. Whilst the majority of studies were symptomatic children brought for clinical care, a small number of studies included asymptomatic PCR positive children at time of test. We again omitted $\mathrm{Hu}$ et al. ${ }^{113}$ as this study population focused on asymptomatic children only. We estimated that overall, 3.8\% (95\% CI: $1.5-6.0 \%)$ of children who were COVID-19 positive had severe or critical symptoms pooled across studies (Fig. 5). The estimated $\tau^{2}$ (between-trial-variance) was 0.0013 (95\%CI: $\left.0.0003-0.0049\right)$ and $\mathrm{I}^{2}$ of $91.30 \%(95 \%$ CI: 72.83-97.47), which indicates that most of the variability between studies is due to heterogeneity rather than chance, but that overall variance is small. A funnel plot of these studies is presented in Fig. S3 in the Supplementary Material showing reasonable symmetry. 


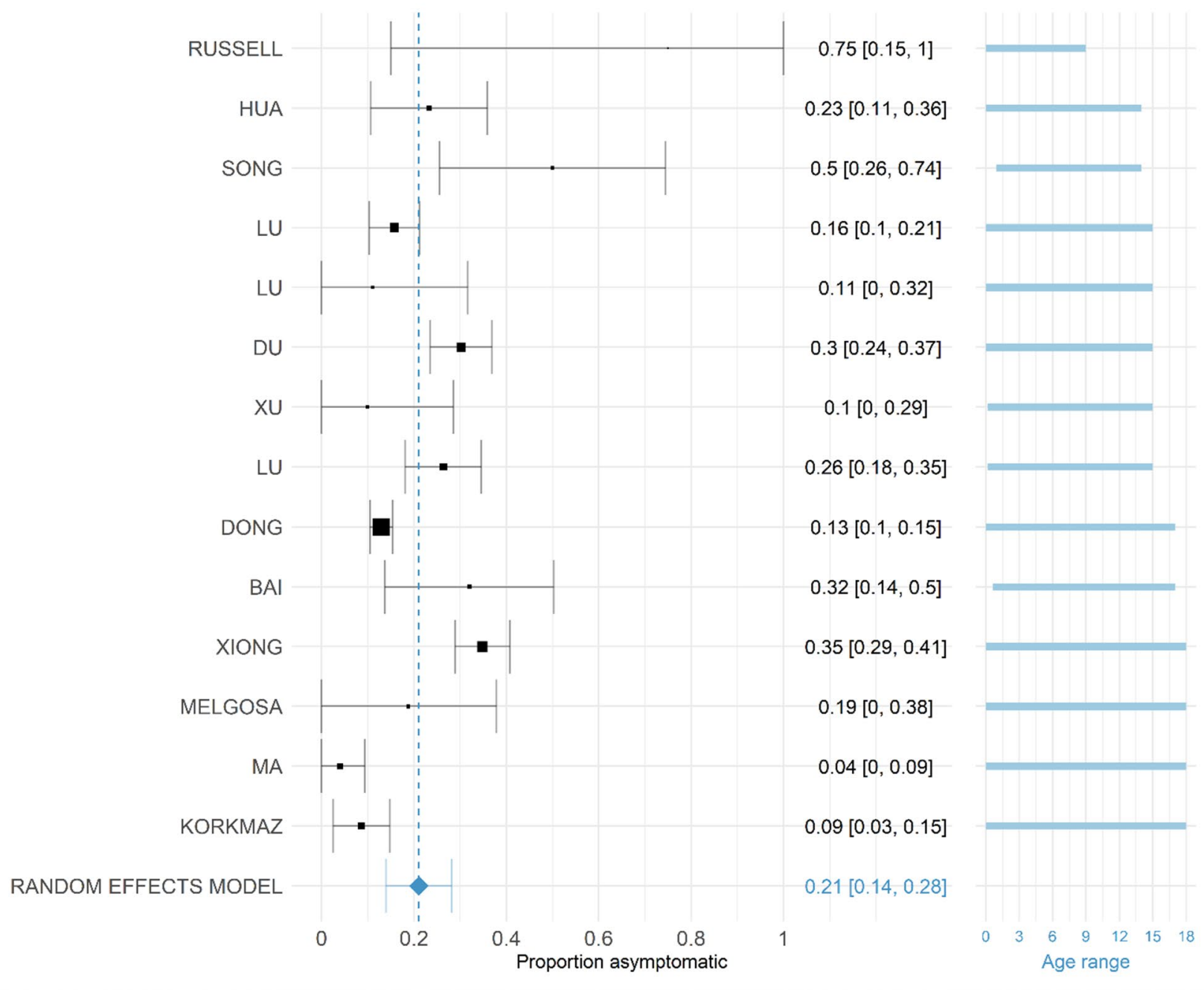

Figure 3. Proportion of SARS-CoV-2 positive children who are defined as asymptomatic at the time of the study in each published study. The random effects model result is given at the bottom indicated by a blue diamond. The squares are proportional in size to the number of COVID-19 positive individuals in the study. All studies were conducted in 2020. The labels on the left provide first author, the labels on the right give point estimate and confidence interval of the asymptomatic proportion estimated. Studies are ordered by the mean of the age range with age range given in blue on the right. Studies were included where recruitment criteria were clear and unbiased.

Transmissibility. We did not identify any studies that were designed specifically to measure SARS-CoV-2 transmissibility in children. As such, there is limited quantitative evidence to understand whether children are less likely to transmit SARS-CoV-2 to others compared to adults.

We identified one case series ${ }^{52}$ that confirmed SARS-CoV-2 transmission from an infant to both parents. Amongst paediatric cases identified in Ireland who attended school during their pre-symptomatic and symptomatic periods of infection $(n=3)$, no instances of onward transmission to either children or adults were identified ${ }^{118}$. Danis et al. ${ }^{94}$ detailed contact tracing of a cluster of cases in a French ski chalet. One paediatric case had a large number of contacts within a school setting (112 contacts) whilst symptomatic. However, contact tracing efforts did not identify any instances of onward transmission. Zachariah et al. ${ }^{102}$ reported two parents in New York, USA, developing symptoms consistent with COVID-19 whilst visiting their hospitalised child, although we note the parents could have been infected outside the hospital or by other hospitalised individuals. A large-scale contact tracing study in South Korea estimated that rates of infection were higher for contacts in households where the index patient was $10-19$ years old (18.6\%, 95\% CI: $14.0-24.0 \%)$ compared to $11.8 \%$ (95\% CI: $11.2-12.4 \%$ ) of all household contacts of COVID-19 index cases ${ }^{119}$.

\section{Discussion}

We identified 128 studies that provided information on the early impact of the COVID-19 pandemic on children and their potential role in transmission that met our eligibility criteria. Our study focused on studies published in the first eight months of the pandemic and represent knowledge and key information gaps early in the pandemic 


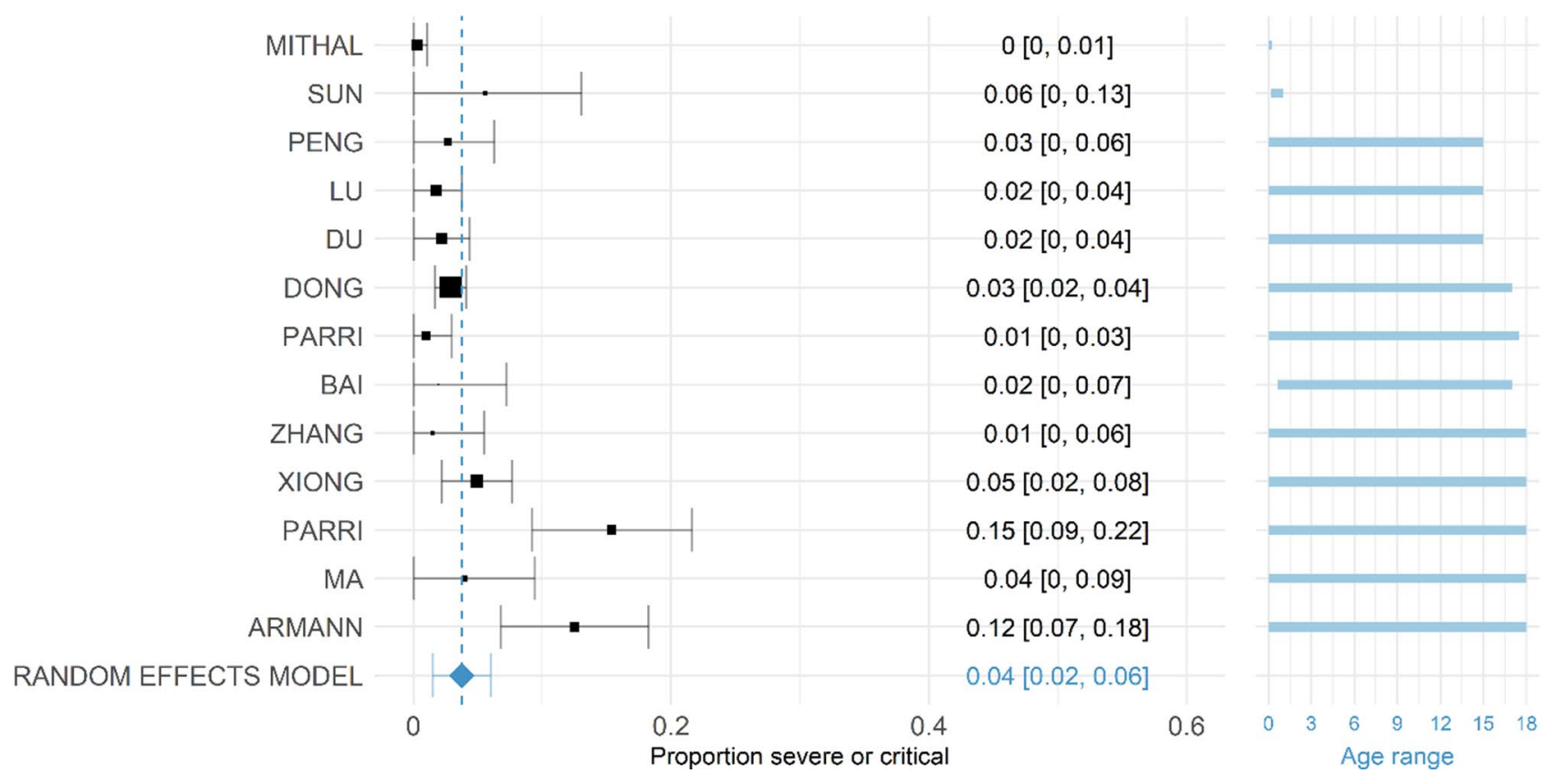

Figure 4. Proportion of COVID-19 positive children who were defined as severe or critical in each available study. The random effects model result is given at the bottom indicated by a blue diamond. The squares are proportional in size to the number of COVID-19 positive individuals in the study. All studies were conducted in 2020. The labels on the left provide first author, the labels on the right give point estimate and confidence interval of the proportion. Studies are ordered by the mean of the age range with age range given in blue on the right.

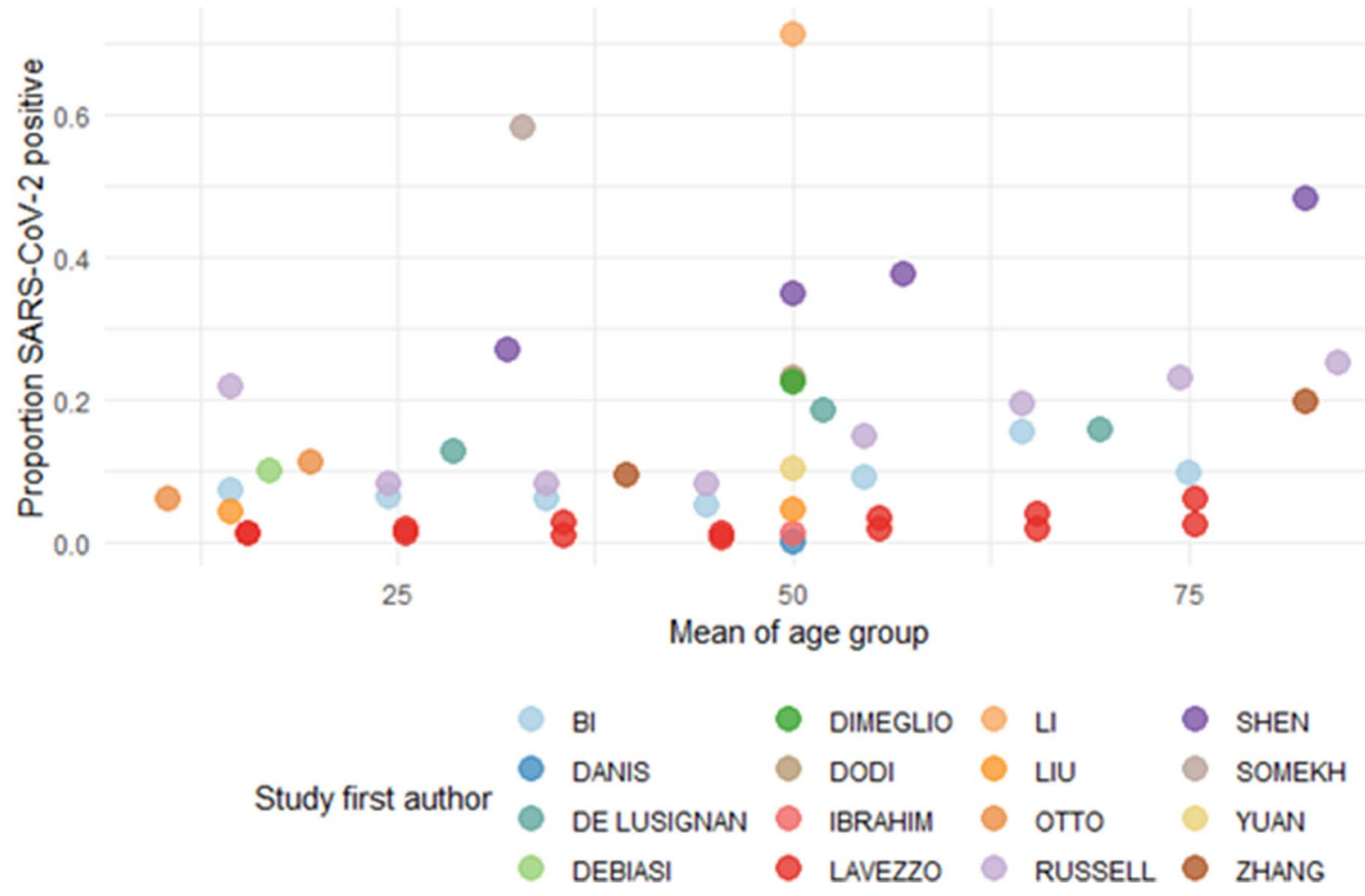

Figure 5. The age-specific prevalence shown as the proportion of confirmed SARS-CoV-2 cases by the mean age of the group. Studies were included if the maximum age was $>18$ (i.e. they included both children and adults) and estimated the prevalence of infection in the cohort. 
of a novel pathogen. Most studies were from China, Europe, and North America and there were no eligible studies from low- and middle-income countries notably from South America or Africa.

Although we were not able to estimate a pooled estimate for age-specific attack rates from the studies identified, they present a mixed picture of comparable, lower, or higher attack rates than adults depending on study setting ${ }^{17,61}$. Population-based PCR screening in Iceland ${ }^{18}$ and Italy ${ }^{75}$ and a seroprevalence survey in Geneva, Switzerland ${ }^{70}$ suggested that young children (5-9 years) were less susceptible to SARS-CoV-2 infection. A more recent hospital-based study in Italy found that children carried the virus less frequently than adults ${ }^{120}$. This agrees with a recent meta-analysis that included non-peer reviewed studies, which also estimated a lower susceptibility to infection in children and adolescents with a pooled odds ratio of 0.56 (95\% CI: $0.37-0.85)^{121,122}$. Similarly a study carried out using household data in Bnei Brak in Israel found that children were less susceptible to SARSCoV-2 infection that adults Other meta-analyses investigating data on the age of index cases and their contacts found no significant difference in susceptibility by age. However, when this was limited to household settings only, Thompson et al. found that adults were statistically significantly more susceptible to SARS-CoV-2 infection compared to children ${ }^{123}$. Jing et al. found similar age-dependent susceptibility in household settings ${ }^{124}$.

There is considerable variation in seroprevalence by age in studies published from multiple countries and settings. Across the USA, 8 out of 10 sites reported the lowest seroprevalence amongst individuals 18 years and younger. However, the sample sizes for children were small so it was difficult to accurately estimate seroprevalence in young children ${ }^{125,126}$. In Tokyo, Japan, no children recruited from two community clinics tested seropositive compared to an overall IgG seropositivity of $3.83 \%$ (95\% CI: $2.76-5.16 \%)^{127}$. However, other studies have reported no differences in seropositivity between children and adults in Argentina ${ }^{128}$, Spain ${ }^{129}$, French Guiana ${ }^{130}$ , Germany ${ }^{131}$, and Italy ${ }^{132}$. Dingens et al. ${ }^{133}$ suggest that seroprevalence studies in children only are not able to quantify relative susceptibility compared to adults, but that the frequency of seropositivity is comparable to the overall incidence. Recent studies showing rapid waning of antibodies, particularly following mild symptoms which are more likely in children, may complicate the picture presented by seroprevalence surveys and their interpretation regarding susceptibility to infection ${ }^{134,135}$.

Adding to the body of evidence that SARS-CoV-2 infection in children are less severe than in adult populations, we estimated from 14 early studies that $21.1 \%$ (95\% CI: 14.0-28.1\%) of SARS-CoV-2 infections in children were asymptomatic. These studies were mainly paediatric cohort studies that swabbed children based on their recent exposure history with a confirmed COVID-19 patient. A small number of studies were retrospective or a case series, detailed in the Supplementary Material. Furthermore, our pooled estimate across 13 studies of the proportion of children with confirmed severe or critical COVID-19 symptoms was low at 3.8\% (95\% CI: 1.5-6.0\%). Most of the 13 studies were based on symptomatic children brought to hospital for clinical care and only a small number of studies included asymptomatic PCR positive children at time of test. These estimates are consistent with recent findings from South Korea where $22.0 \%$ of SARS-CoV-2 positive children remained asymptomatic for the duration of infection and only $3 \%$ of cases were severe ${ }^{136,137}$. However, modelled estimates of the clinical fraction by age using data from 6 countries estimated that almost $80 \%$ of infections in children aged 10-19 years did not develop clinical symptoms i.e., were either asymptomatic or developed mild symptoms (only $21 \%$ (95\% CrI: $12-31 \%$ ) of infections in 10-19-year-olds leading to clinical symptoms) ${ }^{11}$. These estimates should be interpreted with caution as they rely on data from the early stages of the pandemic during which testing and reporting guidelines in countries were still evolving. The estimated proportion of asymptomatic infections in the population across all ages varies widely between studies. He et al., based on 41 studies of confirmed COVID-19 estimated a pooled percentage 15.6\% (95\% CI, 10.1-23.0\%) infections being asymptomatic with significant heterogeneity noted among studies ${ }^{138}$. Another meta-analysis by Zhang et al. ${ }^{139}$ based on early data from the pandemic across all ages estimated pooled rates of intensive care unit admission, acute respiratory distress syndrome, and death of $10.9 \%, 18.4 \%$, and $4.3 \%$ respectively.

It is important to note that this systematic review is based on studies conducted early in the pandemic, predominantly within China. Recent large-scale population-based studies run by the Office for National Statistics ${ }^{140}$ and REACT- $1^{141}$ in the UK have suggested that the proportion of asymptomatic infections may be as high as $67 \%$ across all age groups in the UK. However, this figure also includes individuals who did not respond to questions related to symptoms and pre-symptomatic individuals for the ONS and REACT-1 studies, respectively.

As of November 29th 2020, children still represented less than 13\% of overall COVID-19 cases reported to the European Centre for Disease Prevention and Control and deaths among cases under 18 years were extremely uncommon $^{3}$. This is indicative that SARS-CoV-2 infections amongst children may be less symptomatic or severe than adults as testing policies across Europe thus far have prioritised symptomatic or hospitalised cases. Only a minority of children have required hospital care in the UK with only $1.5 \%$ (310 out of 20,133) of patients in the UK aged $<18$ years ${ }^{9}$. These patterns were also observed in countries affected early on in the pandemic such as China and Italy with few child-hospitalisations ${ }^{142}$. Although we did not consider fatality estimates in this study, deaths are also highly age-dependent with low case and infection fatality estimates in children ${ }^{8,143,144}$.

There were limited studies that addressed the transmissibility of children but there was evidence of onward transmission from paediatric index cases ${ }^{52}$ and rates of COVID-19 being higher amongst household contacts of children in South Korea ${ }^{119}$. Contrastingly, detailed contact-tracing of secondary contacts of a child in France with a large number of contacts across 3 schools did not identify any secondary cases ${ }^{94}$. There were also no secondary cases reported in a school setting in Ireland ${ }^{118}$. Similarly, a seroprevalance study in Germany found no transmission from an index-person less 18 years to a household contact ${ }^{131}$. Milder symptoms in children may limit how much virus is expelled, given viral loads in children and adults may be comparable ${ }^{145,146}$, and therefore, how infectious children are. However, studies have shown that a substantial amount of transmission occurs before the onset of symptoms $s^{24,26,147,148}$, suggesting the relationship between transmissibility and symptoms is complex. A recent meta-analysis estimating secondary attack rates by age of the index case and their contact found no 
significant difference by age in transmissibility. When this was limited to household studies there was weak but not statistically significant evidence that children were less transmissible than adults ${ }^{123}$.

Overall, early evidence suggests that children are less likely to transmit SARS-CoV-2 compared to adults. A cluster-based study from Japan did not identify any children aged 0-19 years as a probable primary case of a cluster ${ }^{149}$, a national study in South Korea reported very low secondary household attack rates of $0.5 \%(95 \%$ CI: $0.0-2.6 \%$ ) from paediatric index cases ${ }^{150}$, and a prospective study in New South Wales, Australia, similarly identified very few instances of onward transmission from a paediatric index case ${ }^{151}$. A detailed study from Tamil Nadu and Andhra Pradesh, India, based on data from 575,071 tested contacts of 84,965 confirmed cases found that the probability of transmission was assortative by age with the strongest effects observed in children aged $0-14$ years and adults aged 65 years and above $e^{152}$.

Most countries implemented full or partial school-closures during the first wave of the pandemic. As schools and other educational institutions re-open across the world, school outbreaks have been increasingly reported, with a large outbreak resulting in a $13.2 \%$ attack rate in secondary school in Israel ${ }^{153}$, and 41 out of 825 primary, secondary and trade schools in Berlin reporting an outbreak of COVID-19 within 2 weeks of reopening ${ }^{154-156}$. However, it is difficult to determine whether transmission occurred primarily in schools or whether pupils were infected at home, or in other social settings. Nevertheless, high attack rates of $44 \%$ reported at a youth camp in Georgia, USA suggests that SARS-CoV-2 can transmit readily in young populations ${ }^{157}$. It is likely that school outbreaks will mirror increasing prevalence in the community itself ${ }^{158}$. Whether schools themselves are the drivers of transmission is still unknown, particularly with many containment measures such as cohorts implemented since reopening.

There are a number of limitations to our study. By the end of the review period (July 2020), there were no studies from Africa or South America that met the inclusion criteria. Contact patterns and household structures may differ substantially in these settings from the predominantly high-income countries considered here, which may result in differences that we have not captured. Although we have estimated the pooled proportion asymptomatic based on the values reported by the study authors, we could not assess whether individuals went on to develop symptoms as very few studies reported the length of follow-up, or loss to follow-up. As such, the definition of asymptomatic may vary between included studies, affecting the estimate. Most of the studies considered were undertaken when non-pharmaceutical interventions, including school closures, case isolation, workplace closures and other social distancing measures, were implemented. The substantial change in contact patterns and the increased mixing within households may mean that children have had fewer opportunities for contact and this decreased the chances of becoming infected or transmitting the virus. Therefore, contact tracing studies have likely disproportionately identified transmission within the household ${ }^{39}$. As restrictions are lifted, we may expect to see a larger role of children in transmission as contact rates will significantly increase. For both population-based infection surveys and seroprevalence studies, the number of children sampled was small and very few studies differentiated between young children and adolescents who may have different risk profiles. Finally, children may be more likely to be tested depending on healthcare seeking behaviour of parents or because in general they may be more prone to illness causing influenza-like illness symptoms. Both factors may contribute in a higher asymptomatic proportion. This review considers only those studies published early in the pandemic. The newly emerging strains of SARS-CoV-2 may exhibit different properties to the earlier circulating strains, such as higher transmissibility in children or changes in severity profiles ${ }^{159}$, which warrant further investigation.

\section{Conclusions}

With many countries across the world now in their second or third wave of the pandemic, there is increasing evidence that children are susceptible to SARS-CoV-2 infection, although perhaps to a lesser extent than adults. It is clear, however, that many children experience clinically mild disease or remain asymptomatically infected. Although severe disease in children does occur, fatalities due to COVID-19 remain rare. Whilst there is evidence to suggest that children are capable of transmitting SARS-CoV-2, more comprehensive contact-tracing studies combined with serosurveys are needed to quantify their transmissibility relative to adults and determine whether they contribute significantly to the outbreaks. Studies showing school reopening can address these data gaps and have begun to show the role of children in the pandemic, although conclusions around the role of children in transmission are still mixed ${ }^{153,160-163}$. It is critical that testing regimes and study protocols are in place that will allow us to better understand the role of children in this pandemic.

Received: 8 December 2020; Accepted: 10 June 2021

Published online: 06 July 2021

\section{References}

1. World Health Organization. WHO Director-General's opening remarks at the media briefing on COVID-19-11 March 2020. https://www.who.int/dg/speeches/detail/who-director-general-s-opening-remarks-at-the-media-briefing-on-covid-19---11march-2020. Accessed September 30th 2020.

2. European Centre for Disease Prevention and Control. COVID-19 situation update worldwide, as of 22 October 2020. https:// www.ecdc.europa.eu/en/geographical-distribution-2019-ncov-cases. Accessed May 19th 2020.

3. ECDC. COVID-19 in children and the role of school settings in COVID-19 transmission. 2020. https://www.ecdc.europa.eu/ en/publications-data/children-and-school-settings-covid-19-transmission.

4. UNESCO. School closures caused by Coronavirus (Covid-19). 2020. https://en.unesco.org/covid19/educationresponse. Accessed October 1st 2020.

5. UNESCO. Global tracking of COVID-19 caused school closures and re-openings. 2020. https://en.unesco.org/sites/default/files/ unesco-map-covid-19-caused-school-closures-and-reopening-methodological-note-en.pdf. Accessed October 12020. 
6. Flaxman, S. et al. Estimating the effects of non-pharmaceutical interventions on COVID-19 in Europe. Nature 584, 257-261 (2020).

7. Swann, O. V. et al. Clinical characteristics of children and young people admitted to hospital with covid-19 in United Kingdom: Prospective multicentre observational cohort study. BMJ 370, m3249 (2020).

8. Verity, R. et al. Estimates of the severity of coronavirus disease 2019: a model-based analysis. Lancet Infect. Dis. 20(6), 669-677 (2020).

9. Docherty, A. B. et al. Features of 20133 UK patients in hospital with covid-19 using the ISARIC WHO Clinical Characterisation Protocol: Prospective observational cohort study. BMJ 369, m1985 (2020).

10. Armann, J. P. et al. Hospital admission in children and adolescents with COVID-19. Dtsch Arztebl Int. 117, 373-374 (2020).

11. Davies, N. G. et al. Age-dependent effects in the transmission and control of COVID-19 epidemics. Nat. Med. 26(8), 1205-1211 (2020).

12. European Centre for Disease Prevention and Control. Epidemiology of COVID-19. https://www.ecdc.europa.eu/en/covid-19/ latest-evidence/transmission.

13. Hoang, A. et al. COVID-19 in 7780 pediatric patients: A systematic review. EClinicalMedicine 24, 100433 (2020).

14. Götzinger, F. et al. COVID-19 in children and adolescents in Europe: a multinational, multicentre cohort study. Lancet Child Adolesc. Heal. 4(9), 653-661 (2020).

15. Jarvis, C. I. et al. Quantifying the impact of physical distance measures on the transmission of COVID-19 in the UK. BMC Med. 18, $124(2020)$

16. Carsetti, R. et al. The immune system of children: The key to understanding SARS-CoV-2 susceptibility?. Lancet Child Adolesc. Health 4, 414-416 (2020).

17. Bi, Q. et al. Epidemiology and transmission of COVID-19 in 391 cases and 1286 of their close contacts in Shenzhen, China: A retrospective cohort study. Lancet Infect Dis. 20(8), 911-919 (2020).

18. Gudbjartsson, D. F. et al. Spread of SARS-CoV-2 in the Icelandic Population. N. Engl. J. Med. 382(24), 2302-2315 (2020).

19. Arora, R. K. et al. SeroTracker: a global SARS-CoV-2 seroprevalence dashboard. Lancet Infect. Dis. 21(4), e75-e76 (2020).

20. SeroTracker. https://serotracker.com/Dashboard. Accessed September 30th 2020.

21. Salvatore, P. P. et al. Recent increase in COVID-19 cases reported among adults aged 18-22 years-United States, May 31-September 5, 2020. MMWR Morb. Mortal. Wkly. Rep. 69(39), 1419 (2020).

22. The Guardian. Younger women 'bearing brunt' of second wave of Covid in UK / World news | The Guardian. https://www.thegu ardian.com/world/2020/sep/22/younger-women-bearing-brunt-of-second-wave-of-covid-in-uk. Accessed September 30th 2020.

23. Qiu, H. et al. Clinical and epidemiological features of 36 children with coronavirus disease 2019 (COVID-19) in Zhejiang, China: An observational cohort study. Lancet Infect. Dis. 20(6), 689-696 (2020).

24. Buitrago-Garcia, D. et al. Occurrence and transmission potential of asymptomatic and presymptomatic SARS-CoV-2 infections: A living systematic review and meta-analysis. PLoS Med. 17, e1003346 (2020).

25. Tong, Z. D. et al. Potential presymptomatic transmission of SARS-CoV-2, Zhejiang Province, China, 2020. Emerg. Infect. Dis. 26, 1052-1054 (2020).

26. He, X. et al. Temporal dynamics in viral shedding and transmissibility of COVID-19. Nat. Med. 26, 672-675 (2020).

27. Rothe, C. et al. Transmission of 2019-NCOV infection from an asymptomatic contact in Germany. N. Engl. J. Med. 382, 970-971 (2020).

28. National Heart Lung and Blood Institute. Study Quality Assessment Tools. https://www.nhlbi.nih.gov/health-topics/study-quali ty-assessment-tools. Accessed September 28th 2020.

29. Viechtbauer, W. Conducting meta-analyses in $R$ with the metafor package. J. Stat. Softw. 36, 1-48 (2010).

30. Fitzjohn R., et al. Orderly: Lightweight Reproducible Reporting 2020.

31. Li, H., Chen, K., Liu, M., Xu, H. \& Xu, Q. The profile of peripheral blood lymphocyte subsets and serum cytokines in children with 2019 novel coronavirus pneumonia. J. Infect. 81(1), 115-120 (2020).

32. Xu, X. W. et al. Clinical findings in a group of patients infected with the 2019 novel coronavirus (SARS-Cov-2) outside of Wuhan, China: retrospective case series. BMJ 368, m606 (2020).

33. Song, W. et al. Clinical features of pediatric patients with coronavirus disease (COVID-19). J. Clin. Virol. 127, 104377 (2020).

34. Song, R. et al. Clinical and epidemiological features of COVID-19 family clusters in Beijing, China. J. Infect. 81(2), e26-e30 (2020).

35. Xia, W. et al. Clinical and CT features in pediatric patients with COVID-19 infection: Different points from adults. Pediatr. Pulmonol. 55(5), 1169-1174 (2020).

36. Shi, Y. et al. A quickly, effectively screening process of novel corona virus disease 2019 (COVID-19) in children in Shanghai, China. Ann. Transl. Med. 8(5), 241 (2020).

37. Wu, H. et al. Clinical and immune features of hospitalized pediatric patients with coronavirus disease 2019 (COVID-19) in Wuhan, China. JAMA Netw Open. 3(6), e2010895 (2020).

38. Zheng, F. et al. Clinical characteristics of children with coronavirus disease 2019 in Hubei, China. Curr Med Sci. 40(2), 275-280 (2020).

39. Zhang, J. et al. Changes in contact patterns shape the dynamics of the COVID-19 outbreak in China. Science (80-) 368(6498), 1481-1486 (2020).

40. Xiong, X. L., Wong, K. K., Chi, S. Q., Zhou, A. F., Tang, J. Q., Zhou, L. S., et al. Comparative study of the clinical characteristics and epidemiological trend of 244 COVID-19 infected children with or without GI symptoms. Gut. 2020; PG.

41. Lu, X. et al. SARS-CoV-2 infection in children. N. Engl. J. Med. 382(17), 1663-1665 (2020).

42. Hua, C. Z. et al. Epidemiological features and viral shedding in children with SARS-CoV-2 infection. J. Med. Virol. 92(11), 2804-2812 (2020).

43. Li, Y. et al. Comparison of Hospitalized Patients with pneumonia caused by COVID-19 and influenza A in children under 5 years. Int. J. Infect. Dis. 98, 80-83 (2020).

44. Yuan, C. et al. Viral loads in throat and anal swabs in children infected with SARS-CoV-2. Emerg. Microbes Infect. 9(1), 1233-1237 (2020).

45. Du, W. et al. Persistence of SARS-CoV-2 virus RNA in feces: A case series of children. J. Infect. Public Heal. 13(7), 926-931 (2020).

46. Sun, D. et al. SARS-CoV-2 infection in infants under 1 year of age in Wuhan City, China. China. World J. Pediatr. 16(3), 260-266 (2020).

47. Lu, Y. et al. Symptomatic Infection is Associated with Prolonged Duration of Viral Shedding in Mild Coronavirus Disease 2019: A Retrospective Study of 110 Children in Wuhan. Pediatr. Infect. Dis. J. 39(7), e95-e99 (2020).

48. Chen, Z. et al. Childhood COVID-19: a multi-center retrospective study. Clin. Microbiol. Infect. 26(9), 1260-e1 (2020).

49. Du, H. et al. Clinical characteristics of 182 pediatric COVID-19 patients with different severities and allergic status. Allergy 76(2), 510-532 (2020).

50. Xiong, X., Chua, G. T., Chi, S., Wah Kwan, M. Y., Sang Wong, W. H., Zhou, A., et al. A comparison between Chinese children infected with COVID-19 and with SARS. J. Pediatr. 2020; PG-.

51. Zhao, C., Xu, Y., Zhang, X., Zhong, Y., Long, L., Zhan, W., et al. Public health initiatives from hospitalized patients with COVID19, China. J. Infect. Public Heal. 2020; PG-. 
52. Cai, J., Xu, J., Lin, D., Yang, Z., Xu, L., Qu, Z., et al. A case series of children with 2019 novel coronavirus infection: Clinical and epidemiological features. Clin. Infect. Dis. 2020; PG-.

53. Gao, Q. et al. The epidemiological characteristics of 2019 novel coronavirus diseases (COVID-19) in Jingmen, Hubei, China. Med 99(23), e20605 (2020).

54. Ma, H. et al. A single-center, retrospective study of COVID-19 features in children: a descriptive investigation. BMC Med. 18(1), $123(2020)$.

55. Ma, Y. et al. Characteristics of asymptomatic patients with SARS-CoV-2 infection in Jinan China. Microbes Infect. 22, 212-217 (2020).

56. Asfahan, S., Deokar, K., Dutt, N., Niwas, R., Jain, P., \& Agarwal, M. Extrapolation of mortality in COVID-19: Exploring the role of age, sex, co-morbidities and health-care related occupation. Monaldi Arch. Chest Dis. 2020;90(2), PG-.

57. Zhang, B., Liu, S., Zhang, J., Xiao, J., Zhu, S., Dong, Y., et al. Children hospitalized for coronavirus disease 2019 (COVID-19): A multicenter retrospective descriptive study. J Infect. 2020; PG-.

58. Zhao, W., Wang, Y., Tang, Y., Zhao, W., Fan, Y., Liu, G., et al. Characteristics of children with reactivation of SARS-CoV-2 infection after hospital discharge. Clin. Pediatr. 2020; 9922820928057.

59. Shen, N., Zhu, Y., Wang, X., Peng, J., Liu, W., Wang, F., et al. Characteristics and diagnosis rate of 5630 subjects receiving SARSCoV-2 nucleic acid tests from Wuhan, China. JCI Insight. 2020;5(10), PG-.

60. Zhang, C. et al. Clinical and epidemiological characteristics of pediatric SARS-CoV-2 infections in China: A multicenter case series. PLoS Med. 17(6), e1003130 (2020).

61. Liu, T., Liang, W., Zhong, H., He, J., Chen, Z., He, G., et al. Risk factors associated with COVID-19 infection: a retrospective cohort study based on contacts tracing. Emerg. Microbes Infect. 2020; 1-31.

62. Lu, Y., Wen, H., Rong, D., Zhou, Z. \& Liu, H. Clinical characteristics and radiological features of children infected with the 2019 novel coronavirus. Clin. Radiol. 75(7), 520-525 (2020).

63. Chen, J., Zhang, Z. Z., Chen, Y. K., Long, Q. X., Tian, W. G., Deng, H. J., et al. The clinical and immunological features of pediatric COVID-19 patients in China. Genes Dis. 2020; PG-.

64. Zhang, L. \& Huang, S. Clinical features of 33 cases in children infected with SARS-CoV-2 in Anhui Province, China-A multicenter retrospective cohort study. Front. Public Heal. 8, 255 (2020).

65. Bai, K., Liu, W., Liu, C., Fu, Y., Hu, J., Qin, Y., et al. Clinical analysis of 25 novel coronavirus infections in children. Pediatr. Infect. Dis. J. 2020; PG-.

66. Dong, X., Cao, Y. Y., Lu, X. X., Zhang, J. J., Du, H., Yan, Y. Q. et al. Eleven faces of coronavirus disease 2019. Allergy 2020; PG-.

67. Du, W., Yu, J., Wang, H., Zhang, X., Zhang, S., Li, Q., et al. Clinical characteristics of COVID-19 in children compared with adults in Shandong Province, China. Infection 2020; $1-8$.

68. Dong, Y., Dong, Y., Mo, X., Hu, Y., Qi, X., Jiang, F., et al. Epidemiology of COVID-19 among children in China. Pediatrics 2020; PG-.

69. He, G., Sun, W., Fang, P., Huang, J., Gamber, M., Cai, J., et al. The clinical feature of silent infections of novel coronavirus infection (COVID-19) in Wenzhou. J. Med. Virol. 2020; PG-.

70. Stringhini, S., Wisniak, A., Piumatti, G., Azman, A. S., Lauer, S. A., Baysson, H., et al. Seroprevalence of anti-SARS-CoV-2 IgG antibodies in Geneva, Switzerland (SEROCoV-POP): a population-based study. Lancet. 2020.

71. Dimeglio, C., Mansuy, J. M., Charpentier, S., Claudet, I. \& Izopet, J. Children are protected against SARS-CoV-2 infection. J. Clin. Virol. 128, 104451 (2020).

72. Oualha, M. et al. Severe and fatal forms of COVID-19 in children. Arch. Pediatr. 27(5), 235-238 (2020).

73. de Lusignan, S., Dorward, J., Correa, A., Jones, N., Akinyemi, O., Amirthalingam, G., et al. Risk factors for SARS-CoV-2 among patients in the Oxford Royal College of General Practitioners Research and Surveillance Centre primary care network: a crosssectional study. Lancet Infect. Dis. 2020; PG-.

74. Harman, K. et al. Ethnicity and COVID-19 in children with comorbidities. Lancet Child Adolesc. Heal. 4(7), e24-e25 (2020).

75. Lavezzo, E., Franchin, E., Ciavarella, C., Cuomo-Dannenburg, G., Barzon, L., Del Vecchio, C., et al. Suppression of a SARS-CoV-2 outbreak in the Italian municipality of Vo? Nature. 2020; PG-

76. Parri, N., Lenge, M., \& Buonsenso, D. Children with Covid-19 in Pediatric Emergency Departments in Italy. N. Engl. J. Med. 2020; PG-

77. Dodi, I. et al. SARS-CoV-2 infection in children in Parma. Acta Biomed. 91(2), 214-215 (2020).

78. Garazzino, S., Montagnani, C., Donà, D., Meini, A., Felici, E., Vergine, G., et al. Multicentre Italian study of SARS-CoV-2 infection in children and adolescents, preliminary data as at 10 April 2020. Euro Surveill. 2020;25(18), PG-.

79. De Ioris, M. A., Scarselli, A., Ciofi Degli Atti, M. L., Ravà, L., Smarrazzo, A., Concato, C., et al. Dynamic viral SARS-CoV-2 RNA shedding in in children: Preliminary data and clinical consideration of Italian regional center. J. Pediatr. Infect. Dis. Soc. 2020; PG-.

80. Moratto, D., Giacomelli, M., Chiarini, M., Savarè, L., Saccani, B., Motta, M., et al. Immune response in children with COVID-19 is characterized by lower levels of T cell activation than infected adults. Eur. J. Immunol. 2020; PG-.

81. L'Huillier, A. G., Torriani, G., Pigny, F., Kaiser, L., Eckerle, I. Culture-competent SARS-CoV-2 in nasopharynx of symptomatic neonates, children, and adolescents. Emerg. Infect. Dis. 2020;26(10), PG-.

82. Brambilla, I., Castagnoli, R., Caimmi, S., Ciprandi, G. \& Luigi, M. G. COVID-19 in the pediatric population admitted to a tertiary referral hospital in northern Italy: Preliminary clinical data. Pediatr. Infect. Dis. J. 39(7), e160 (2020).

83. Valente, P., Iarossi, G., Federici, M., Petroni, S., Palma, P., Cotugno, N., et al. Ocular manifestations and viral shedding in tears of pediatric patients with coronavirus disease 2019: a preliminary report. J. AAPOS. 2020; PG-.

84. Parri, N., Magistà, A. M., Marchetti, F., Cantoni, B., Arrighini, A., Romanengo, M., et al. Characteristic of COVID-19 infection in pediatric patients: early findings from two Italian Pediatric Research Networks. Eur. J. Pediatr. 2020, 1-9.

85. Talarico, V., Nicoletti, A., Sabetta, L., Minchella, P. \& Raiola, G. Preliminary epidemiological analysis on children and adolescents with novel coronavirus disease (2019-nCoV) in a central area of Calabria region. Acta Biomed. 91(2), 232-233 (2020).

86. Gujski, M. et al. Epidemiological analysis of the first 1389 Cases of COVID-19 in Poland: A preliminary report. Med. Sci. Monit. 26, e924702 (2020).

87. Hildenwall, H., Luthander, J., Rhedin, S., Hertting, O., Olsson-Åkefeldt, S., Melén, E., et al. Paediatric COVID-19 admissions in a region with open schools during the two first months of the pandemic. Acta Paediatr. 2020; PG-.

88. Posfay-Barbe, K. M., Wagner, N., Gauthey, M., Moussaoui, D., Loevy, N., Diana, A., et al. COVID-19 in children and the dynamics of infection in families. Pediatrics. 2020; PG-.

89. Schwierzeck, V., König, J. C., Kühn, J., Mellmann, A., Correa-Martínez, C. L., Omran, H., et al. First reported nosocomial outbreak of severe acute respiratory syndrome coronavirus 2 (SARS-CoV-2) in a pediatric dialysis unit. Clin. Infect. Dis. 2020; PG-.

90. Melgosa, M. et al. SARS-CoV-2 infection in Spanish children with chronic kidney pathologies. Pediatr. Nephrol. 35(8), 1521-1524 (2020).

91. de Ceano-Vivas, M., Martín-Espín, I., Del Rosal, T., Bueno-Barriocanal, M., Plata-Gallardo, M., Ruiz-Domínguez, J. A., et al. SARS-CoV-2 infection in ambulatory and hospitalised Spanish children. Arch Dis. Child. 2020; PG-. 
92. González Cortés, R., García-Salido, A., Roca Pascual, D., Slöcker Barrio, M., \& de Carlos Vicente, J. C. A multicenter national survey of children with SARS-CoV-2 infection admitted to Spanish Pediatric Intensive Care Units. Intensive Care Med. 2020; $1-3$.

93. García-Salido, A., Leoz-Gordillo, I., Martínez de Azagra-Garde, A., Nieto-Moro, M., Iglesias-Bouzas. M. I., García-Teresa, M. Á., et al. Children in critical care due to severe acute respiratory syndrome coronavirus 2 infection: Experience in a Spanish hospital. Pediatr Crit Care Med. 2020; PG-.

94. Danis, K., Epaulard, O., Bénet, T., Gaymard, A., Campoy, S., Bothelo-Nevers, E., et al. Cluster of coronavirus disease 2019 (Covid-19) in the French Alps, 2020. Clin. Infect. Dis. 2020; PG-.

95. US Centers for Disease Control and Prevention. Severe outcomes among patients with coronavirus disease 2019 (COVID19)-United States, February 12-March 16, 2020. MMWR Morb. Mortal. Wkly. Rep. 69(12), 343-346 (2020).

96. Rha, B., Lively, J. Y., Englund, J. A., Staat, M. A., Weinberg, G. A., Selvarangan, R., et al. SARS-CoV-2 Infections in ChildrenMulti-Center Surveillance, United States, January-March 2020. J. Pediatr. Infect. Dis. Soc. 2020; PG-.

97. Zachariah, P., Halabi, K. C., Johnson, C. L., Whitter, S., Sepulveda, J., \& Green, D. A. Symptomatic infants have higher nasopharyngeal SARS-CoV-2 viral loads but less severe disease than older children. Clin. Infect. Dis. 2020; PG-.

98. DeBiasi, R. L., Song, X., Delaney, M., Bell, M., Smith, K., Pershad, J., et al. Severe COVID-19 in children and young adults in the Washington, DC Metropolitan Region. J. Pediatr. 2020; PG-.

99. Ranabothu, S., Onteddu, S., Nalleballe, K., Dandu, V., Veerapaneni, K., \& Veerapandiyan, A. Spectrum of COVID-19 in Children. Acta Paediatr. 2020; PG-

100. Mithal, L. B., Machut, K. Z., Muller, W. J., \& Kociolek, L. K. SARS-CoV-2 Infection in Infants Less than 90 Days Old. J. Pediatr. 2020; PG-.

101. Otto, W. R., Geoghegan, S., Posch, L. C., Bell, L. M., Coffin, S. E., Sammons, J. S., et al. The epidemiology of SARS-CoV-2 in a pediatric healthcare network in the United States. J. Pediatr. Infect. Dis. Soc. 2020; PG-.

102. Zachariah, P., Johnson, C. L., Halabi, K. C., Ahn, D., Sen, A. I., Fischer, A., et al. Epidemiology, clinical features, and disease severity in patients with coronavirus disease 2019 (COVID-19) in a Children's Hospital in New York City, New York. JAMA Pediatr. 2020; e202430.

103. Wu, Q., Xing, Y., Shi, L., Li, W., Gao, Y., Pan, S., et al. Coinfection and other clinical characteristics of COVID-19 in Children. Pediatrics. 2020;146(1) PG-.

104. Mannheim, J., Gretsch, S., Layden, J. E., \& Fricchione, M. J. Characteristics of hospitalized pediatric COVID-19 Cases-Chicago, Illinois, March-April 2020. J. Pediatr. Infect. Dis. Soc. 2020; PG-.

105. Foster, C. E. et al. Coronavirus Disease 2019 in Children Cared for at Texas Children's Hospital: Initial clinical characteristics and outcomes. J. Pediatr. Infect. Dis. Soc. 9, 373 (2020).

106. Shekerdemian, L. S. et al. Characteristics and outcomes of children with coronavirus disease 2019 (COVID-19) infection admitted to US and Canadian Pediatric Intensive Care Units. JAMA Pediatr. 174, 868 (2020).

107. $\mathrm{Xu}$, Y. et al. Characteristics of pediatric SARS-CoV-2 infection and potential evidence for persistent fecal viral shedding. Nat. Med. 26(4), 502-505 (2020).

108. Russell, T. W., Hellewell, J., Jarvis, C. I., van Zandvoort, K., Abbott, S., Ratnayake, R., et al. Estimating the infection and case fatality ratio for coronavirus disease (COVID-19) using age-adjusted data from the outbreak on the Diamond Princess cruise ship, February 2020. Euro Surveill. 2020;25(12) PG-.

109. Ibrahim, L. F., Tosif, S., McNab, S., Hall, S., Lee, H. J., Lewena, S., et al. SARS-CoV-2 testing and outcomes in the first 30 days after the first case of COVID-19 at an Australian children's hospital. Emerg Med Australas. 2020; PG-.

110. Somekh, E. et al. The role of children in the dynamics of intra family coronavirus 2019 spread in densely populated area. Pediatr. Infect. Dis. J. 39, e202-e204 (2020).

111. Korkmaz, M. F., Türe, E., Dorum, B. A. \& K1lıç, Z. B. The epidemiological and clinical characteristics of 81 children with COVID19 in a pandemic hospital in Turkey: An observational cohort study. J. Korean Med. Sci. 35(25), e236 (2020).

112. Han, M. S. et al. Viral RNA load in mildly symptomatic and asymptomatic children with COVID-19, Seoul. Emerg. Infect. Dis. 26(10), 2467 (2020)

113. Hu, Z. et al. Clinical characteristics of 24 asymptomatic infections with COVID-19 screened among close contacts in Nanjing, China. Sci. China Life Sci. 63(5), 706-711 (2020).

114. Peng, H. et al. Coronavirus disease 2019 in children: Characteristics, antimicrobial treatment, and outcomes. J. Clin. Virol. 128, $104425(2020)$

115. Terrin, N., Schmid, C. H. \& Lau, J. In an empirical evaluation of the funnel plot, researchers could not visually identify publication bias. J. Clin. Epidemiol. 58, 894-901. https://doi.org/10.1016/J.JCLINEPI.2005.01.006 (2005).

116. Guan, W. J. et al. Clinical characteristics of coronavirus disease 2019 in China. N. Engl. J. Med. 382(18), 1708-1720 (2020).

117. Sterne, J. A. C. et al. Recommendations for examining and interpreting funnel plot asymmetry in meta-analyses of randomised controlled trials. BMJ 343, d4002. https://doi.org/10.1136/bmj.d4002 (2011).

118. Heavey, L., Casey, G., Kelly, C., Kelly, D., McDarby, G. No evidence of secondary transmission of COVID-19 from children attending school in Ireland, 2020. Euro Surveill. 2020;25(21) PG-

119. Park, Y. J., Choe, Y. J., Park, O., Park, S. Y., Kim, Y.-M., Kim, J., et al. Contact Tracing during coronavirus disease outbreak, South Korea, 2020. Emerg Infect. Dis. J. 2020;26 10 PG-

120. Milani, G. P. et al. Frequency of children vs adults carrying severe acute respiratory syndrome coronavirus 2 asymptomatically. JAMA Pediatr. 175, 193. https://doi.org/10.1001/jamapediatrics.2020.3595 (2021).

121. Viner, R. M. et al. Susceptibility to SARS-CoV-2 infection among children and adolescents compared with adults. JAMA Pediatr. 10, $011101(2020)$.

122. Goldstein, E., Lipsitch, M. \& Cevik, M. On the effect of age on the transmission of SARS-CoV-2 in households, schools, and the community. J. Infect. Dis. 223, 362-369. https://doi.org/10.1093/infdis/jiaa691 (2021).

123. Thompson, H. A. et al. Severe acute respiratory syndrome coronavirus 2 (SARS-CoV-2) setting-specific transmission rates: A systematic review and meta-analysis. Clin. Infect. Dis. https://doi.org/10.1093/cid/ciab100 (2021).

124. Jing, Q.-L. et al. Household secondary attack rate of COVID-19 and associated determinants in Guangzhou, China: A retrospective cohort study. Lancet Infect Dis. 20, 1141-1150 (2020).

125. Havers, F. P., Reed, C., Lim, T., Montgomery, J. M., Klena, J. D., Hall, A. J., et al. Seroprevalence of Antibodies to SARS-CoV-2 in 10 Sites in the United States, March 23-May 12, 2020. JAMA Intern Med. 2020.

126. US Centers for Disease Control and Prevention. CDC COVID Data Tracker. https://covid.cdc.gov/covid-data-tracker/?CDC AA_refVal=https\%3A\%2F\%2Fwww.cdc.gov\%2Fcoronavirus\%2F2019-ncov\%2Fcases-updates\%2Fcommercial-labs-interactiveserology-dashboard.html\#serology-surveillance. Accessed September 30th 2020.

127. Takita, M., Matsumura, T., Yamamoto, K., Yamashita, E., Hosoda, K., Hamaki, T., et al. Regional difference in seroprevalence of SARS-CoV-2 in Tokyo: Results from the community point-of-care antibody testing. medRxiv. 2020;:2020.06.03.20121020.

128. Figar, S. et al. Community-Level SARS-CoV-2 Seroprevalence Survey in Urban Slum Dwellers of Buenos Aires City, Argentina: A Participatory Research (Cold Spring Harbor Laboratory Press, New York, 2020).

129. Sant Joan de Deu Barcelona Children's Hospital. First conclusions of the COVID-19 investigation in children. 2020.

130. Flamand, C., Enfissi, A., Bailly, S., Sarmento, C. A., Beillard, E., Gaillet, M., et al. Seroprevalence of anti-SARS-CoV-2 IgG at the epidemic peak in French Guiana. 
131. Galow, L. et al. Lower household transmission rates of SARS-CoV-2 from children compared to adults. J. Infect.. https://doi.org/ 10.1016/j.jinf.2021.04.022 (2021).

132. Milani, G. P. et al. Frequency of asymptomatic carriers of SARS-CoV-2 among children and adults after school reopening. Ital. J. Pediatr. 47, 65. https://doi.org/10.1186/s13052-021-01016-5 (2021).

133. Dingens, A. S., Crawford, K. H., Adler, A., Steele, S. L., Lacombe, K., Eguia, R., et al. Seroprevalence of SARS-CoV-2 among children visiting a hospital during the initial Seattle outbreak. medRxiv Prepr. Serv. Heal. Sci. 2020.

134. Ibarrondo, F. J. et al. Rapid decay of anti-SARS-CoV-2 antibodies in persons with mild covid-19. N. Engl. J. Med. 383, 1085-1087 (2020).

135. Burgess, S., Ponsford, M. J. \& Gill, D. Are we underestimating seroprevalence of SARS-CoV-2?. The BMJ. 370, m3364 (2020).

136. Han, M. S. et al. Clinical characteristics and viral RNA detection in children with coronavirus disease 2019 in the Republic of Korea. JAMA Pediatr. 175, 73 (2020).

137. Alvarado, G. R. et al. Symptom characterization and outcomes of sailors in isolation after a COVID-19 outbreak on a US aircraft carrier. JAMA Netw. Open 3, e2020981 (2020).

138. He, J., Guo, Y., Mao, R. \& Zhang, J. Proportion of asymptomatic coronavirus disease 2019: A systematic review and meta-analysis. J Med Virol. 93, 26326 (2020).

139. Zhang, J. J. Y., Lee, K. S., Ang, L. W., Leo, Y. S. \& Young, B. E. Risk factors for severe disease and efficacy of treatment in patients infected with COVID-19: A systematic review, meta-analysis, and meta-regression analysis. Clin. Infect. Dis. 71, 2199 (2020).

140. ONS. Coronavirus (COVID-19) infections in the community in England-Office for National Statistics.

141. Department of Health and Social Care. REACT-1: real-time assessment of community transmission of coronavirus (COVID-19) in August 2020-GOV.UK.

142. Ludvigsson, J. F. Systematic review of COVID-19 in children shows milder cases and a better prognosis than adults. Acta Paediatrica Int. J. Paediatr. 2020.

143. Moraga, P., Ketcheson, D. I., Ombao, H. C. \& Duarte, C. M. Assessing the age- and gender-dependence of the severity and case fatality rates of COVID-19 disease in Spain. Wellcome Open Res. 5, 117 (2020).

144. O’Driscoll, M., Ribeiro Dos Santos, G., Wang, L., Cummings, D. A. T., Azman, A. S., Paireau, J., et al. Age-specific mortality and immunity patterns of SARS-CoV-2 infection in 45 countries. medRxiv. 2020.

145. Corman, V. M., Jones, T. C., Mühlemann, B., Veith, T., Biele, G., Zuchowski, M., et al. An analysis of SARS-CoV-2 viral load by patient age. medRxiv. 2020;:2020.06.08.20125484.

146. Baggio, S., L'Huillier, A. G., Yerly, S., Bellon, M., Wagner, N., Rohr, M., et al. SARS-CoV-2 viral load in the upper respiratory tract of children and adults with early acute COVID-19. Clin. Infect. Dis. 2020.

147. Tindale, L. C. et al. Evidence for transmission of covid-19 prior to symptom onset. Elife 9, 1-34 (2020)

148. Arons, M. M. et al. Presymptomatic SARS-CoV-2 infections and transmission in a skilled nursing facility. N. Engl. J. Med. 382, 2081-2090 (2020).

149. Furuse, Y. et al. Clusters of coronavirus disease in communities, Japan, January-April 2020. Emerg. Infect. Dis. 26, 2176-2179 (2020).

150. Kim J, Choe YJ, Lee J, Park YJ, Park O, Han MS, et al. Role of children in household transmission of COVID-19. Arch Dis. Child. $2020 ; 1-3$.

151. Macartney, K., Quinn, H. E., Pillsbury, A. J., Koirala, A., Deng, L., Winkler, N., et al. Transmission of SARS-CoV-2 in Australian educational settings: a prospective cohort study. Lancet Child Adolesc. Heal. 2020.

152. Laxminarayan, R., Wahl, B., Reddy Dudala, S., Gopal, K., Mohan, C., Neelima, S., et al. Epidemiology and transmission dynamics of COVID-19 in two Indian states. Science (80- ). 2020.

153. Stein-Zamir, C. et al. A large COVID-19 outbreak in a high school 10 days after schools' reopening, Israel, May 2020. Eurosurveillance 25, $2001352(2020)$.

154. Link G. A risky game with health and lives as schools reopen throughout Germany-World Socialist Web Site.

155. CBC News. 41 schools report coronavirus in Berlin | CBC News.

156. Ehrhardt, J. et al. Transmission of SARS-CoV-2 in children aged 0-19 years in childcare facilities and schools after their reopening in May 2020, Baden-Württemberg, Germany. Eurosurveillance 25, 2001587 (2020).

157. Szablewski, C. M., Chang, K. T., Brown, M. M., Chu, V. T., Yousaf, A. R., Anyalechi, N., et al. Morbidity and mortality weekly report SARS-CoV-2 transmission and infection among attendees of an overnight Camp-Georgia, June 2020.

158. Fong, M., Cowling, B., Leung, G. \& Wu, P. Letter to the editor: COVID-19 cases among school-aged children and school-based measures in Hong Kong, July 2020. Eurosurveillance 25, 2001671 (2020).

159. Singapore warns children susceptible to virus variants, shuts schools.

160. No evidence of association between schools and SARS-CoV-2 second wave in Italy.

161. Larosa, E., Djuric, O., Cassinadri, M., Cilloni, S., Bisaccia, E., Vicentini, M., et al. Secondary transmission of COVID-19 in preschool and school settings in northern Italy after their reopening in September 2020: a population-based study. Eurosurveillance 25(49), 2001911. https://doi.org/10.2807/1560-7917.ES.2020.25.49.2001911 (2020).

162. Ratmann, O., Bhatt, S., Flaxman, S. Implications of a highly transmissible variant of SARS-CoV-2 for children. Arch. Dis. Child., 321093. https://doi.org/10.1136/archdischild-2021-321903 (2021).

163. Volz, E., Mishra, S., Chand, M., Barrett, J. C., Johnson, R., Geidelberg, L., et al. Assessing transmissibility of SARS-CoV-2 lineage B.1.1.7 in England. Nature 593(7858), 266-269. https://doi.org/10.1038/s41586-021-03470-x (2021).

\section{Acknowledgements}

We would like to acknowledge the members of the Imperial College COVID-19 response team. All authors except HB acknowledge funding from the MRC Centre for Global Infectious Disease Analysis (reference MR/ R015600/1), jointly funded by the UK Medical Research Council (MRC) and the UK Foreign, Commonwealth and Development Office (FCDO), under the MRC/FCDO Concordat agreement and is also part of the EDCTP2 programme supported by the European Union; and acknowledges funding by Community Jameel. HJTU acknowledges funding from Imperial College London through her Imperial College Research Fellowship. EJ is an Imperial College Research Fellow and is jointly funded by Rosetrees Trust and The Stoneygate Trust.

\section{Author contributions}

K.A.M.G., T.M., H.J.T.U., G.C.-D., H.B., S.B., C.W., N.I., E.J., M.K., A.M. performed the literature search and screening. T.M., S.B., E.J. performed the quality assessment. N.I., H.J.T.U., S.B. wrote the first manuscript version. K.A.M.G. performed the meta-analysis. S.R. and N.M.F. provided project supervision. K.A.M.G., T.M., H.J.T.U., G.C.-D., H.B., S.B., C.W., N.I., E.J., M.K., A.M., S.R., N.M.F., L.W. reviewed the final draft. 


\section{Competing interests}

The authors declare no competing interests.

\section{Additional information}

Supplementary Information The online version contains supplementary material available at https://doi.org/ 10.1038/s41598-021-92500-9.

Correspondence and requests for materials should be addressed to K.A.M.G.

Reprints and permissions information is available at www.nature.com/reprints.

Publisher's note Springer Nature remains neutral with regard to jurisdictional claims in published maps and institutional affiliations.

(c) (1) Open Access This article is licensed under a Creative Commons Attribution 4.0 International License, which permits use, sharing, adaptation, distribution and reproduction in any medium or format, as long as you give appropriate credit to the original author(s) and the source, provide a link to the Creative Commons licence, and indicate if changes were made. The images or other third party material in this article are included in the article's Creative Commons licence, unless indicated otherwise in a credit line to the material. If material is not included in the article's Creative Commons licence and your intended use is not permitted by statutory regulation or exceeds the permitted use, you will need to obtain permission directly from the copyright holder. To view a copy of this licence, visit http://creativecommons.org/licenses/by/4.0/.

(C) The Author(s) 2021, corrected publication 2021 